\title{
Adaptation techniques of an urban planning due to climate change
}

\author{
Natalia Bakaeva $^{1}$, Maria Suvorova $^{2 *}$, Roman Sheps ${ }^{3}$, and Alexandra Kormina ${ }^{4}$ \\ ${ }^{1}$ Moscow State University of Civil Engineering, Yaroslavskoe shosse, 26, Moscow, 129337, Russia \\ ${ }^{2}$ Belgorod State Technological University named after V.G. Shukhov, 46, Kostyukova street, \\ Belgorod, 308012, Russia \\ ${ }^{3}$ Voronezh State Technical University, 84, 20 let Oktyabrya street, Voronezh, 394006, Russia \\ ${ }^{4}$ Southwest State University, 94, 50 let Oktyabrya street, Kursk, 305040, Russia
}

\begin{abstract}
In this paper there is reviewed a concept of adaptation of an urban planning to the changing climate conditions. The statements of the Framework Convention on Climate Change, UN FCCC, which are actively discussed these days in conditions of new challenges, determine a necessity of applying scientifically reasoned approaches to the landscape development and city transformation considering the climate change in the urban environment. There are discussed statements of climate change adapted concept of the urban planning and are reviewed examples of urban solutions corresponding to these statements. The authors are convinced that problem solving of the climate change adapted urban planning requires an interdisciplinary approach, embracing multiple scientific directions such as ecological, urban, social, technical and technological. In this aspect the concept of adaptation the urban planning to volatile climate conditions represent a long-term strategy of the urban development, which is, first of all, requires a preparation of a roadmap and then decision making, which would conduce to forming a fully comfortable and safe urban environment.
\end{abstract}

\section{Introduction}

The global problem of climate change and, consequently, the actions for the human race survival are actively discussed by the international scientific community and, thus, are extremely relevant for a few decades. Thereby, Wilhelmi O.V., Hayden M.H. [1], Gwilliam J., Fedeski M., Lindley S., Theuray N. [2] deliberate a question of a methodology of an urban environment assessment from the point of possibility of dangerous risk factors appearance, elicited by the ineffective human actions and the global climate change in their works. The similar questions are deliberated in the papers of Cui L. and Shi J. [3] (University of Connecticut).

The adaptation of the urban environment to the conditions of global climatic changes is discussed in detail in the works of Peet E., Mcevoy D. (Stockholm Environment Institute, Oxford), Dugord PA, Lauf S., Schuster C., Kleinschmit B. (Humboldt-Universität zu Berlin) and Alexander P.J., Fealy R., Mills G.M. on the example of the largest cities in

\footnotetext{
* Corresponding author: marykrutilova@gmail.com
} 
Europe (London, Berlin and Dublin) [4-6]. In their works, the authors highlight common negative factors associated with climate change, affecting the global mechanisms of interaction within the ecosystems of these cities, and ways to overcome them.

The study of the urban microclimate and the influence of the morphology of buildings and other factors on it is also the subject of study of more than one scientific team. This problem has received considerable attention in the works of Matzarakis A. [7], Erell E. [8], Pearlmutter D. [9].

Within the framework of the scientific knowledge of urban climatology there is still a little-studied phenomenon associated with the formation of thermal zones, in which, due to thermal pollution of large cities, a specific local air circulation is formed, called the urban wind. In the temperature field of a city or other residential territory, this anomaly leads to the formation of a well-known microclimatic effect - the "urban heat island".

The urban heat island has both direct and indirect consequences, including social, economic and environmental ones, which cannot but affect the planning and design decisions. The research works of Dixon P.G., Mote T.L., [10], Keiko Masumoto [11], Kochin A. [12] are devoted to the study of this phenomenon.

In the researches of Varentsov M.I. and Konstantinov P.I. [13] from the Moscow State University named after M.V. Lomonosov and A.M. Obukhov Institute of Atmospheric Physics of the Russian Academy of Sciences there are presented the results of experimental studies on the study of climate, based on numerical modeling and observations of the climatic parameters of Moscow.

As the results of the scientific analysis of the problem under consideration have shown, almost all urban planning decisions made in the context of climate change affect urban planning, and issues related to urban planning restrictions should be considered as a separate criterion in land development and urban design projects along with the issues of sustainable development of urbanized areas. Thus, a hypothesis arises that the urban environment should be adaptive, and urban planning and design solutions should contribute to the transformation of urban space and the adaptability of the population to various situations associated with the risks of climate change. Solving such a problem requires an interdisciplinary approach.

\section{Problem statement}

The purpose of the article is to analyze the concepts of urban planning and innovative urban planning solutions in order to identify trends in the adaptation of the urban environment to climate change. This formulation of the problem attracts many specialists involved in the formation of an urban planning environment for life in the context of new challenges. Among the precedents in urban planning practice, there can be marked out specific design solutions and numerous architectural experiments performed for urban objects based on the principles of adaptation.

\section{Materials and methods}

Sustainable development of the urbanized areas in the context of this innovative concept is one of the priorities of the urban planning activity [14]. The problem of limited use of spatial and territorial resources expresses the need for the search for new, relevant solutions in the field of urban planning, as well as technological innovations associated with the transformation of the human life environment into a comfortable and safe one.

The research on this issue reveals the following concepts in urban planning: 
1) "Sustainable city" in the context of the innovative paradigm as a challenge to civilization. This concept is the basic trend of modern urban planning, which involves the preservation of environmental integrity and resource conservation in combination with the use of new technologies and various innovations.

2) The concept of an "adaptability of the spatial environment", implying the adaptation of the environment to changing external conditions. The concept defines new planning principles, new types of project tasks and means of their implementation, reforming adaptation methodologies.

3) The concept of biosphere compatibility of cities and settlements developing people. The concept determines that Nature is an absolute value, which is higher than a human and he is its element, and any action against Nature is perceived as opposing [15].

4) The concept of "smart city". "Smart city" is a, first of all, urban planning concept of ensuring a high quality of life perceived by the population; the concept of creating conditions for satisfying rational human needs with the use of information and communication technologies [16].

\section{Results and discussion}

Considering the adaptation measures of urban planning in the context of climate change, it should be noted that there have historically been close and complex links between urban planning and the climatic factors of cities. To date, long-term observations of the climate have provided the basis for the formation of a regulatory technical base for architectural and construction climatology, which is used both in planning and in the development of cities and rural settlements. Based on the peculiarities of the natural and climatic conditions of the region and local microclimatic conditions, the main urban planning requirements for the planning and development of populated areas are formed [17]. Taking into account the correction of climatic conditions, the main typological features of residential and mass public buildings - houses, schools, kindergartens, etc. have been standardized.

At the same time, the urban planning features of the urban area determine the factors of the formation of the microclimate of the city: changes in the relief due to urban development; the difference in the thermophysical properties of the surfaces of urban construction elements and the natural environment; the difference in the albedo of the underlying surfaces of the city territories and their surroundings; artificial heat flows; air pollution; reduction in evaporation due to asphalt pavements and overregulation of precipitation flow; a sharp decrease in surface area with vegetation and natural soil, etc. $[18,19]$. In this connection, urban planning and design are acquiring a new direction in their development - an integrated approach, since urban spaces begin to form in the context of mitigating the effects of climate change and the ability of cities to adapt to climate change.

The factors influencing the emergence of urban planning restrictions in planning and designing an adaptive urban environment today are the circumstances of variability of each type of location which has its own specific microclimate, the meteorological indicators which differ from the characteristics of open space, and in general is characterized by microclimatic flexibility of radiation, temperature and wind conditions as well as insolation and light conditions. In addition, in the urban environment, territorial and spatial resources are already limited due to the existing constructions and layouts, and the adaptive capabilities of the environment are primarily in landscape techniques and climate-adaptive urban design.

Urban planning restrictions in planning and designing an adaptive urban environment in the face of climate change are the permitted uses of land plots established by law and a 
special legal regime for the use and boundaries of land, which are basically reduce the adaptive capabilities of the environment.

Let us formulate the statements that characterize the concept of adaptive urban planning in the context of climate change, which come down to the following:

- Adaptability of the urban environment is considered as a fundamental basis for solving design problems to ensure comfortable and safe conditions for human life;

- Climate adaptation is aimed at improving environmental conditions and controlling the microclimate of the entire environment, considering the individual needs;

- Search for new forms of intra-environment interactions that regulate the parameters of the environment, for example, the development of interactive technologies, an increase in the social responsibility of the population for making decisions on urban planning projects related to climate change;

- Development of means of transformation of elements of the environment to be adapted, from mobile design to transformable architectural objects.

Guided by statements above, we will consider proposals for adaptive urban planning and measures to adapt the urban environment within the framework of climate-adaptive urban design.

Climate-adaptive urban design is the urban planning solutions focused on the arrangement of the territory by transforming urban space and combining spatial elements in such a way as to ensure the protection of the population from the negative effects of climate. Climate-adaptive design takes microclimatic effects into account during summer and winter, but often focuses on counteracting the build-up of city heat in summer. Among the natural influences, urban heat can compromise the habitability of open spaces. In this context, climate-adaptive urban design in urban planning mainly aims to:

- control the amount of solar radiation reaching the public space by providing different gradients of sun and shade;

- use the influence of green spaces on thermal comfort in cities and human bioclimatic parameters;

- consider the effects of wind by providing wind protection in winter or by stimulating ventilation cooling in summer;

- regulate air temperature and relative humidity by combining parameters such as evaporation and aeration;

- optimize heat loss from surfaces by reflecting as much solar radiation as possible and releasing heat.

Due to its social orientation, urban planning activities should cover all aspects of the development of the urban environment. So, within the framework of climate-adaptive and socially oriented design, the authors of the study [20] consider the humanization of space to be the main task based on the need to take into account the rational needs of the urban population. It is obvious that in the conditions of the prevailing consumer lifestyle of an industrial city, i.e. "Supercomfort", individual goods and services become redundant, and urban planning does not meet the rational needs of the population, but the commercial interests of development [21]. Therefore, the conclusion suggests itself that the stage of urban social planning, first of all, should be carried out in regard to the interests of the population.

Four main categories of spatial elements are commonly used to address climateresponsive design challenges: green vegetation, shading devices, surface materials, and aquatic resources. In urban planning it is important to understand how these categories are relevant for a specific area, i.e. how spatial elements are dependent on the urban microclimate.

Vegetation, as an environment-restoring urban system, ensures the comfort of living conditions for people, regulates, within certain limits, the chemical composition of 
atmospheric air and the degree of its pollution, establishes the microclimatic characteristics of urban areas, and reduces the influence of the noise factor. Vegetation, as the central element of the architectural landscape of the environment, performs, first of all, a sanitizing function, changes the tempo and moisture balance. Also, urban green spaces have a beneficial effect on preventing water and wind erosion of soil.

As a source of aesthetic perception, green spaces contribute to the humanization of the urban environment. A person by any means tries to make up for the lack of the natural environment in the city, to form a highly comfortable environment through sometimes even imitation of the natural environment, resorting to landscape design methods (Figure 1).

Trees, shrubs, ground cover plants also add compositional diversity to the appearance of the streets and boulevards of the city and, in the case of coordinated interaction with architectural objects, can positively influence not only the artistic expressiveness of the urban environment, but also provide, first of all, adaptation measures as part of urban planning solutions.

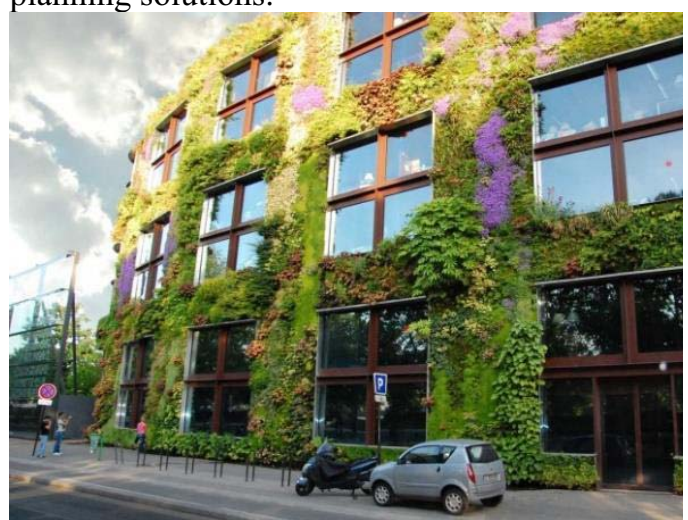

a)

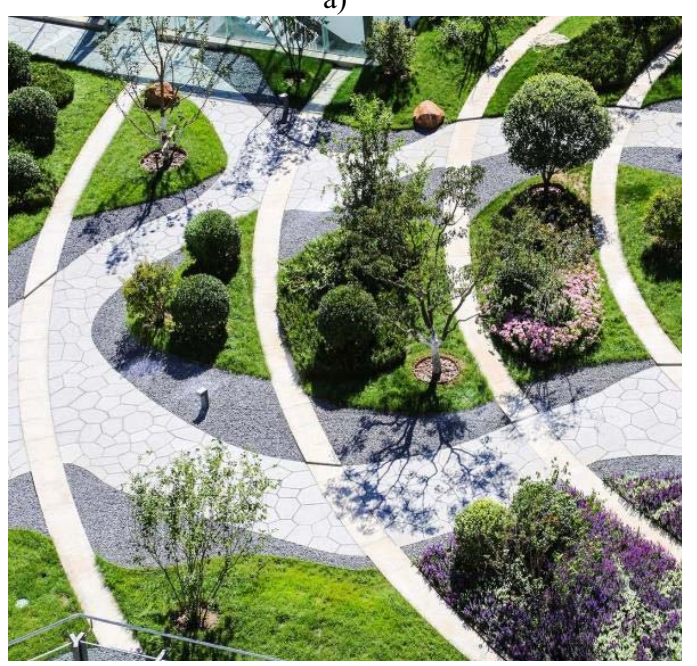

c)

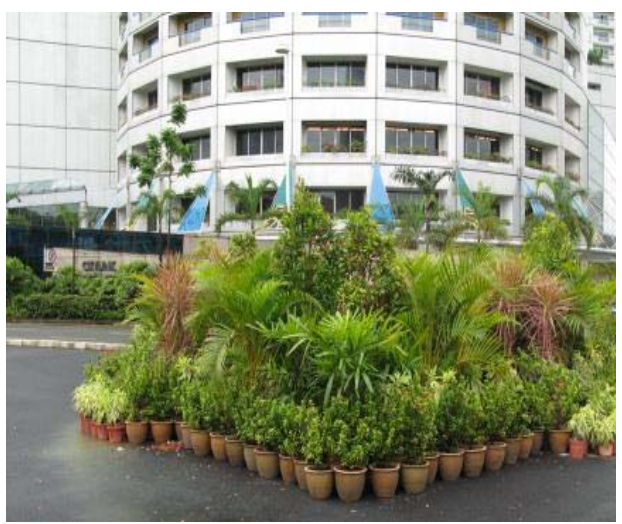

b)

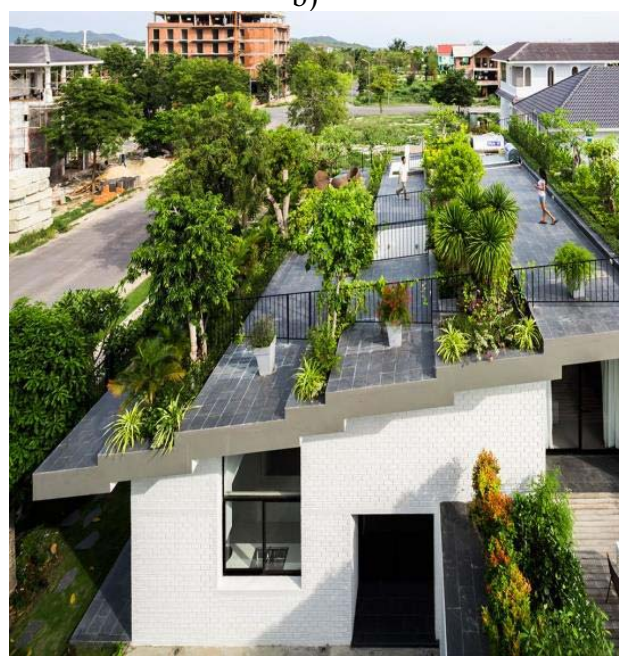

d)

Fig. 1. The examples of city landscaping systems: a) vertical landscaping; b) portable landscaping systems; c) natural silhouettes; d) rooftop gardens.

Artificial shading devices such as umbrellas, awnings, pergolas, panels or hedges are urban solutions that provide localized shade to urban spaces. This contributes to better thermal adaptation of people in the urban environment, and also contributes to the establishment of a dynamic balance between the environment and bioclimatic parameters. 
The creation of a variety of sunny, shady, sheltered subspaces has the potential to increase the use of open public spaces throughout the year. The shade is created using trees, fabric, wood or other material that makes it possible to reduce the temperature and active exposure to sunlight (Figure 2).

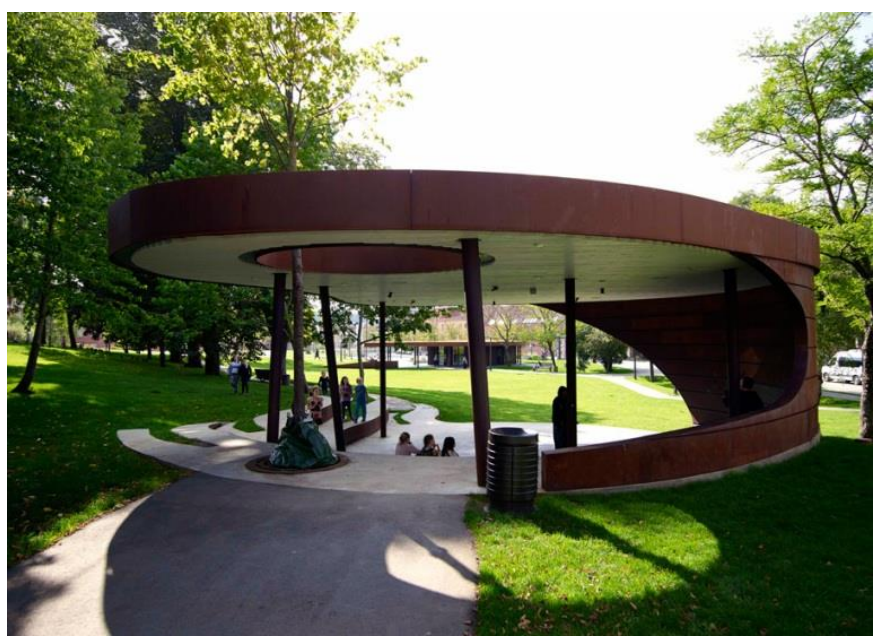

Fig. 2. Landscape architecture platform - shading zone in Maria Park in Vejle, Dutch. Landscape architect Bascon [22]

Given examples from the field of adaptive city spaces are associated with microclimatic changes, albait it is the natural and climatic factor that is the least controllable.

In addition to all aesthetic considerations, surface materials can influence urban microclimate mainly (but not exclusively) through their optical and moisture resistant properties. Surface materials create a difference in albedo (reflectivity) of the underlying surfaces of the city and the surrounding area. Albedo is today an important concept in climate-responsive urban design and environmental management.

Creation of urban landscapes with natural and artificial water bodies aimed at improving the quality of the environment and comfortable living conditions for the population. Characterizing water bodies in the urban environment, first of all, it should be said that water surfaces in the urban landscape are one of the most important ecological and aesthetic components of the natural landscape, and water urban devices occupy a leading place in the formation of a comfortable recreational environment - they affect the microclimate of areas of the territory, reduce the temperature of the surface of the earth, asphalt and air, significantly increase the humidity of air masses, and are also a source of energy. A sparkling calm water surface or a meandering moving ribbon of an artificial stream (Figure 3), fountain jets playing under the sun bring an emotional state of dynamics into the urban landscape and enliven the building landscape. 


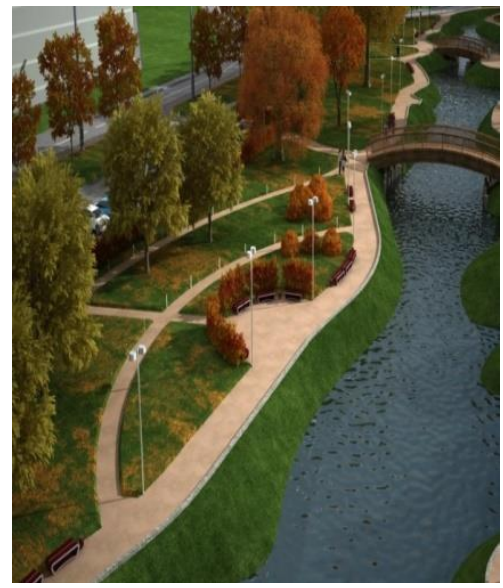

a)



b)

Fig. 3. The examples of city landscapes with: a) artificial water body; b) fountain device

The urban planning concept of a "smart city" implements technologies for systemic (integrated) management of the development and interaction of urban systems and technologies for transforming approaches to the formation of the urban environment and infrastructural development of territories.

One of the trends in adaptive urban planning in regard to the smart city concept is monitoring the state of the urban environment. Within the framework of this concept, adaptive urban planning in the face of climate change can be implemented using technology for tracking microclimatic parameters and pollution factors in real time (online) using automatization systems and tools, as well as part of various smart city services. Further, in the process of making urban planning decisions, the information obtained during the monitoring will be the informational basis for cartographic support and urban planning zoning of the territory - climatic zoning. This direction of applied urban planning analytics indicates the current tasks of forecasting the development of urban areas in the future.

Adaptation mechanisms in urban planning documents. The concept of urban planning considering climate change, first of all, should be reflected in urban planning documents. For the Russian Federation, first of all, the consolidation of the principles of adaptation, transformation and regulation is necessary at the federal level for the development of urban planning documentation in order to reflect the constitutional right of citizens to a safe living environment in the strategic planning of the country's spatial and territorial development. Further support and development of these principles presupposes their introduction into the documents of urban development of different territorial levels. So, at the regional level, the principles of adaptation of the urban environment to climate change should be included in the comprehensive and sectoral schemes of spatial and territorial planning, taking into account the characteristics of each region. At the level of the implementation of municipal authority, the concept of adaptation is directly introduced into master plans and projects for planning the city's territories developed on their basis.

\section{Conclusions}

The current period of global challenges shows that the time has come for a broad discussion and implementation of a new urban planning concept of territorial planning considering climate change. Such a concept is being built today on the principles of adaptation of the 
spatial environment and the adaptability of the population to changing external conditions. Further support and development of these principles presupposes their introduction into territorial planning and urban planning documents. It is necessary to legalize the concept of adaptive urban planning and its inclusion in the process of urban planning activities and in strategic planning. The practical significance of the research results lies in obtaining new knowledge for the development of the considered concept of adaptive urban planning. This modern line of research allows us to outline in the theory of urban planning new approaches to the development of principles for the formation of the urban environment and innovative technological solutions, including: climate-adaptive design, transformation of functionally existing types of public spaces, the use of public low-carbon transport, the introduction of smart city technologies, and others.

This research was carried out under the project 620497-EPP-1-2020-1-RU-EPPJMO-MODULE "Climate change and urban planning: European experience" (CLEUX), funded with support from the European Commission. The findings and opinions reported in this paper reflect the views only of the authors, and the Commission cannot be held responsible for any use which may be made of the information contained in it.

\section{References}

1. O.V. Wilhelmi, M.H. Hayden, Connecting people and place: A new framework for reducing urban vulnerability to extreme heat. Environ. Res. Lett., 5, 014021 (2010)

2. J. Gwilliam, M.H. Fedeski, S. Lindley, N. Theuray, Methods for assessing risk from climate hazards in urban areas. Proc. Inst. Civ. Eng. Munic. Eng. 159, 245-253 (2006)

3. L. Cui, J. Shi, Urbanization and its environmental effects in Shanghai, China. Urban Climate, 2, 1-15 (2012)

4. S.J. Lindley, J.F. Handley, N. Theuray, E. Peet, D. Mcevoy, Adaptation strategies for climate change in the urban environment: Assessing climate change related risk in UK urban areas, J. Risk Res. 9, 543-568 (2006)

5. P.A. Dugord, S. Lauf, C. Schuster, B. Kleinschmit, Land use patterns, temperature distribution, and potential heat stress risk - The case study Berlin, Germany, Comput. Envi-ron. Urban Syst. 48, 86-98 (2014)

6. P.J. Alexander, R. Fealy, G.M. Mills, Simulating the impact of urban development pathways on the local climate: A scenario-based analysis in the greater Dublin region, Ireland. Landsc. Urban Plan. 152, 72-89 (2016)

7. A. Matzarakis, A Note on the Assessment of the Effect of Atmospheric Factors and Components on Humans, November 2020, Atmosphere 11 (1283):1-18 (2020)

8. E. Erell, D. Pearlmutter, D. Boneh, P.B. Kutiel, Effect of high-albedo materials on pedestrian heat stress in urban street canyons. Urban Climate, 10, 367-386 (2014)

9. E. Macline, D. Pearlmutter, M. Schwartz, P. Pech, The French Case Studies, in: Green Neighbourhoods and Eco-gentrification. SpringerBriefs in Environmental Science. (Springer, Cham, 2020)

10. P.G. Dixon, T.L. Mote, Patterns and causes of Atlanta's urban heat island-initiated precipitation. J. Appl. Meteorol. 42, 1273-1284 (2003)

11. K. Masumoto, Urban Heat Islands, in: Armon R., Hänninen O. (eds) Environmental Indicators. (Springer, Dordrecht, 2015) 
12. M.A. Lokoshchenko, I.A. Korneva, A.V. Kochin, A.Z. Dubovetsky, M.A. Novitsky, P.Y. Razin, Vertical extension of the urban heat island above Moscow, Doklady Earth Sciences, 466 (1), 70-74 (2016) (In Russ)

13. P. Konstantinov, M. Varentsov, I. Esau, A high density urban temperature network deployed in several cities of Eurasian Arctic, Environ. Res. Lett. 13(7), 75007 (2018) (In Russ)

14. E.V. Shcherbina, N.V. Danilina, Town planning aspects of designing sustainable urban environment, in Proceedings of Irkutsk state technical university, 11 (94), 183-186 (2014) (In Russ)

15. V.A. Ilyichev, V.I. Kolchunov, N.V. Bakaeva, Urban planning architecture, Russian Journal of Building Construction and Architecture, 4(60), 121-132 (2020) (In Russ)

16. O.B. Ganin, I.O. Ganin, "Smart City": Prospects and Development Trends, in ARS Administrandi, 1, 124-135 (2014) (In Russ)

17. I.S. Shukurov, M. Pirov, Features of the microclimatic mode of the development in the valley kotlovinny relief of the city, in News of higher educational institutions. Construction, 5(725), 102-112 (2019) (In Russ)

18. C.V. Viegas, D.L. Saldanha, A. Bond, J.L.D. Ribeiro, P.M. Selig, Urban land planning: The role of a Master Plan in influencing local temperatures, in Cities 2013, 35, 1-13 (2013)

19. H. Kim, Y. Kim, S. Song, H.W. Lee, Impact of future urban growth on regional climate changes in the Seoul Metropolitan Area, Korea, Ireland. Sci. Total Environ. 571, 355-363 (2016)

20. V.L. Glazychev, O dizayne. Ocherki o teorii i praktike dizayna na Zapade [About design. Essays on the theory and practice of design in the West], Moscow: Iskusstvo (1970) (In Russ)

21. I. Pryadko, I. Lebedev, Preservation of manor and park ensembles within the capital city and the principles of "Green architecture", in E3S Web of Conferences. Topical Problems of Green Architecture, Civil and Environmental Engineering, TPACE, 2019, 04010 (2020)

22. Landezine, Landscape architecture platform, Available at: http://landezine.com/index.php/2015/06/maria-park-by-bascon/maria-park-by-bascon08/ (accessed: 15 February 2021) 